\title{
Review
}

\section{Fostering autonomy: A theory of citizenship, the state and social service delivery}

\author{
Elizabeth Ben-Ishai \\ Pennsylvania State University Press, University Park, 2012, xi+196 pp., \$26.95, \\ ISBN: 978-0271052175 \\ Contemporary Political Theory (2015) 14, e18-e21. doi:10.1057/cpt.2014.6; \\ published online 28 October 2014
}

Elizabeth Ben-Ishai's book is a significant milestone for both political theory and political science. It combines normative theorizing on the liberal ideal of autonomy with copious empirical evidence about how clients are actually treated in social welfare systems today. As a result, the book delivers on Stears' (2005) call for an empirically situated approach to political theory. In the process of critically engaging a wide range of theorists and empirical researchers, Ben-Ishai provides an immanent critique of the embedded wisdom of actually existing approaches to service provision. The results are stunning for both their theoretical insight and practical relevance. This is a book that will be eagerly read and used by normative political theorists and public policy implementation scholars, as well as many others in and out of the academy.

We learn from Ben-Ishai that: (i) much of the writing in normative political theory has oversimplified autonomy as an individualistic ideal in liberal political discourse; (ii) a more sophisticated understanding of autonomy would recognize that it involves relationships with others as much as rights arrogated to the self; (iii) in order to realize this relational understanding of autonomy, we must match concern for individualized personal responsibility with collective political responsibility; and (iv) state provision of services that promote autonomy must involve clients in the design and implementation of services, but so as to enable them to connect the dots for themselves in 'loosely coupled' systems of 'coordinated fragmentation', for only then will we be improving the state's capacity to empower clients to become efficacious democratic citizens on their own terms. In the meantime, social programming that enforces standards of personal responsibility end up today more often than not undermining autonomy more than promoting it.

Ben-Ishai buttresses her argument with an empirically detailed survey across social service venues from welfare-to-work, to pregnancy prevention, to immigration reform, to domestic violence programs, to drug treatment. Referencing statistical

(C) 2015 Macmillan Publishers Ltd. 1470-8914 Contemporary Political Theory Vol. 14, 1, e18-e21 www.palgrave-journals.com/cpt/ 
research, case studies, interpretive accounts and even thought-experiments, she shows how realizing autonomy via state-sponsored social service provision is not only possible but occurring in distinctive instances where policymakers, program managers and clients collaborate to fashion services that are appreciative of the complexities for achieving autonomy among the subordinated, marginalized and oppressed.

Fostering Autonomy is, however, by no means a pollyanna read offering an upbeat story on how social services can help disadvantaged populations achieve autonomy. Ben-Ishai's theory of individualized autonomous action emerging out of and feeding back into embedded social relationships is not only an important theoretical intervention in liberal-democratic discourse, it also of necessity leads to an appreciation that the autonomous person is not someone who is best understood as acting alone without support; rather, s/he is someone who may need more than a little help from their friends to keep on keeping on. For Ben-Ishai, once we come to appreciate the socially embedded and fragile nature of the autonomous individual, we need to be prepared to see people struggling with personal problems as no different from others who are already recognized as autonomous by the dominant culture simply because they can avoid relying on the service system, sometimes only because they can afford not to or are able to keep their problems private. Ben-Ishai shows us that the autonomous individuals are a real-life, flesh-and-blood people, with complexities, problems and struggles of their own. Further, really autonomous individuals do not turn their backs on the community in which they are embedded but instead pay it forward helping others to achieve personal responsibility. Autonomous individuals are self-aware and fully cognizant of their political responsibility to the community that empowered them. And that includes taxpayers and the general citizenry as much as the clients of social service systems.

One of the most impressive things about this first book by a young scholar is how it critically and convincingly engages pre-existing scholarship. Ben-Ishai takes on prominent scholars one after another, building on their work to make her case, taking what she agrees with and explicitly noting what she does not. She accepts the importance of Ronald Dworkin's critique of paternalism in the name of defending the ideal of autonomy for liberal-democratic citizenship. Yet, she chides him for an overly individualistic account that fails to include an appreciation of the indebtedness of personal responsibility to a dense web of social relationships. She values Wendy Brown's as well as Frances Fox Piven and Richard Cloward's critiques of the welfare state as imposing social control in the name of dominant forms of structured power relationships, be they along gender, race or class lines. Yet, she includes considerations from people like Linda Gordon about how the paternalism of the state can in fact be put in service of empowering subordinated groups (though she prefers not to call these particular interventions as simply paternalistic). Ben-Ishai understands Barbara Cruikshank's critique of how various forms of social provision are said to empower the poor but actually end up doing so in disempowering ways; however, she is quick to note that we need to examine in each case whether the empowering 
actually ends up creating disempowerment. She accepts Philippe Bourgois' critique of harm reduction strategies, such as Methadone Maintenance programs, that all too often collapse into disciplinary regimes for managing illicit pleasures, so as to contain them within socially acceptable limits. Yet, she is critical of Bourgois for reducing pleasure to only that which the state has prohibited. There is more to pleasure than what is disallowed. Participants in Methadone Maintenance programs may find much satisfaction, if not sheer joy, in being able to manage their addiction and still participate in mainstream society. Throughout these exchanges, Ben-Ishai puts on a stunning display of active and critical reading, wading through theoretical and empirical literatures to complicate what is autonomy and how it can be realized when social service systems are sensitively designed.

Yet, this magisterial study is really at its best when Ben-Ishai uses the research on current social service practice to complicate our understanding of what autonomy really is and how social provision can be supportive of its realization. She shows that welfare-to-work schemes under the dramatic welfare reforms of the 1990s or immigration restrictions that flowed from those reforms talk a lot about personal responsibility but actually undermine its realization in the people who are affected by those reforms. Ben-Ishai, however, finds that coordinated community response programs for domestic violence survivors demonstrate that protective policies for women need not be patronizing and in fact can be empowering. Harm reduction programs where drug addicts play a significant role in designing and running maintenance programs can in fact not just work but empower addicts to become functioning citizens. Social service systems designed with the nuanced understanding of autonomy that emerges in this book can in fact help promote a more autonomous democratic citizenry who will be better prepared to join with others to more thoroughly realize democratic ideals.

In the end, Ben-Ishai convincingly proves that we can indeed rely on empirical research about what actually happens in social service programs to improve our theorizing about the ideal of the autonomous citizen as the bedrock for liberal democracy. And perhaps more importantly, she even more dramatically proves that we can use nuanced political theorizing as a form of critique to highlight how actually existing social service programming can feasibly be designed and implemented in ways that effectively empower clients to become autonomous citizens.

While by no means a criticism, Ben-Ishai does not discuss the work of everyone who has written insightfully about the issue of autonomy in the welfare state. As great as this book is and as seriously as it engages the theorists of relevance to its distinctive argument, I personally was very much waiting for the author to take on Martha Fineman on autonomy as a ideal for liberal democracies, Kevin Olson on the virtuous cycle of enablement, and Kristin Bumiller on the paradoxes of the state intervention on behalf of women. Ben-Ishai offers such thoughtful critiques of so many others on whose work I have come to rely that I was looking forward to her thoughtful response to the work of these important theorists. It turns out that just as 
autonomy is more complex than we have often allowed ourselves to believe, so is a great book, one that leaves one looking forward to more.

\section{Reference}

Stears, M. (2005) The vocation of political theory: Principles, empirical inquiry and the politics of opportunity. European Journal of Political Theory 4(4): 325-350.

Sanford F. Schram

Hunter College, City University of New York, New York 10065, USA

E-mail: sanford.schram@hunter.cuny.edu 